\title{
Editorial
}

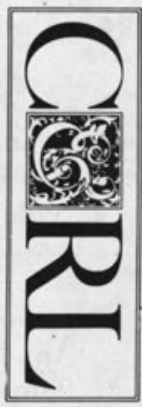

\section{More Alternatives for Scholarly Publishing}

In the March editorial, I discussed resource sharing as a possible alternative to rising serials prices. I now offer two other alternatives: a revised balance between quantity and quality as criteria for judgment in the academy and a redesign of scholarly publishing.

Knowledge expands. In response, journal markets have become increasingly more specialized. Increases in pages, twigs from existing titles, entirely new titles, and additional issues are legitimate sources of price increases. Yet many believe that existing systems encourage and reward the proliferation of knowledge by dividing it into the smallest publishable units. College and university administrators-and I include myself in their number-find quantity easier to judge than quality. Yet the clear result of that comfortable attitude is more articles in more serials at a greater cost, and the misunderstanding discussed in this issue's letters to the editor seems a likely, if not natural, consequence of the emphasis on quantity.

Quality should reign. A recent revision of National Science Foundation grant proposal requirements requests a list of up to five most relevant and five additional publications in place of the usual complete list. This change would emphasize quality in the merit review process. Similarly, Harvard Medical School now allows promotion to professor to be judged on no more than ten papers, associate professor on seven, and assistant on five. ${ }^{1}$ Excellence is to take precedence over numbers. These initiatives toward quality as a more important criterion than quantity offer hope.

The academy should publish. The advent of electronic publishing offers hope for restructuring scholarly publishing. Currently, university faculty are the primary authors of scholarly articles. Especially in the sciences, government funding supports the research reported in these articles. However, the articles themselves are exported to foreign publishers, who sell them back to the originating academic institutions and their libraries at a substantial premium. While the history of this arrangement is reasonable, its continuation is not. In the last issue of CERL, Paul Metz and Paul Gherman described the establishment of a corporation of scholarly publishing as an alternative.

Electronics simplify. The expensive typesetting equipment and the attendant-poorly paid-but expert operators are rapidly ceding to electronic publication systems. The advent of relatively inexpensive desktop publishing, with its ability to support a variety of typefaces and character sets, makes it possible for colleges, universities, and societies to take up again their responsibilities for print journals. Even more exciting is the prospect that many journals and even books will be published electronically. As knowledge becomes more and more specialized, many kinds of resources will be saved. Only the subspecialist will download or print out an article in the subspecialty, whereas currently such articles are delivered to all, regardless of interest.

Actions count. Librarians must actively work toward adopting these solutions. Talk to college and university colleagues and administrators about the consequences of quantity over quality as a criterion. Tie those concerns into your presentations about the need for more 
serials monies. Discuss the possibilities of electronic publication and prepare for its acceptance as legitimate credit in ac- ademia. Through action, hopes can turn into realities.

GLORIANA ST. CLAIR

\section{REFERENCE}

1. Ann Okerson, "NSF Grant Proposal Requirement Revised," ARL Newsletter 154:1-2 (Jan. 4, 1991).

College \& Research Libraries is running a series about the current serials crisis. The series includes a March article by Kenneth Marks, Steven Nielsen, Craig Petersen, and Peter Wagner, a May article by Eldred Smith, a July article by Paul Metz and Paul Gherman, a September article by Ann Okerson, and a November panel of commentators.

\section{IN FORTHCOMING ISSUES OF COLLEGE \& RESEARCH LIBRARIES}

Librarians' Satisfaction with Faculty Status by Marjorie A. Benedict

The Library as a Marketplace of Ideas by Ronald J. Heckart

Academic Librarians and the Library and Information Science Monograph: An Exploratory Study by Peter Hernon

Automation in East Asian Libraries in the United States: A Review and Assessment by Sarah Su-erh Elman

Assessment of Learning Outcomes: A Measure of Progress in Library Literacy by Arlene Greer, Lee Weston, and Mary Alm

Citations in Hypermedia: Maintaining Critical Links by Corinne Jörgensen and Peter Jörgensen

Research Notes

Keyword Searching in an Online Public Access Catalog: Characteristics of Users and Nonusers by Pat Ensor 